\title{
Process and proposal for comprehensive regionalization of Chinese human geography
}

\author{
FANG Chuanglin ${ }^{1,2}$, LIU Haimeng ${ }^{1,2}$, LUO Kui ${ }^{1,2}$, YU Xiaohua ${ }^{1,2}$ \\ 1. Institute of Geographic Sciences and Natural Resources Research, CAS, Beijing 100101, China; \\ 2. College of Resources and Environment, University of Chinese Academy of Sciences, Beijing 100049, China
}

\begin{abstract}
The comprehensive regionalization of Chinese human geography is based on the rules governing regional differentiation of Chinese physical geographic factors. Based on regional differences and similarities in human factors, this study divides the whole country into two levels of relatively independent, complete and organically linked human geographic units. As a fundamental, comprehensive, cutting-edge, practical and important task, the comprehensive regionalization of human geography highlights the characteristics, regional and sub-regional features, complexity and variety of spatial differences between factors of Chinese human geography. It is capable of promoting the development of human geography based on local conditions, providing basic scientific support to national and local development strategies, such as the Belt and Road Strategy, new urbanization and environmental awareness, and creating a sound geopolitical environment in key areas. Using results from existing physical and human geographic zoning studies, and in accordance with the principles of synthesis, dominant factors, the relative consistency of the natural environment, the relative consistency of social and economic development, the consistency of the regional cultural landscape, the continuity of spatial distribution and the integrity of county-level administrative divisions, and taking as its basis the division of human geography into 10 major factors (nature, economy, population, culture, ethnicity, agriculture, transportation, urbanization, the settlement landscape and administrative divisions), this paper constructs an index system for the comprehensive regionalization of Chinese human geography through a combination of top-down and bottom-up zoning and spatial clustering analysis. In this study, Chinese human geography is divided into eight regions and 66 sub-regions. The eight human geography regions are (I) Northeast China, (II) North China, (III) East China, (IV) Central China, (V) South China, (VI) Northwest China, (VII) Southwest China, and (VIII) Qinghai and Tibet. This zoning proposal fills gaps in studies involving the non-comprehensive regionalization of Chinese human geography. Each human geography region and sub-region has different topographical, climatic, ecological, population, urbanization, economic development, settlement landscape, regional cultural and ethno-religious attributes. This proposal on the comprehensive regionalization of Chinese human geography dovetails closely with previous studies on comprehensive regionalization in Chinese physical geography, Chinese economic zoning, and Chinese agricultural zoning. It shows that, under the dual roles of nature and humans, there are
\end{abstract}

Received: 2017-01-07 Accepted: 2017-03-10

Foundation: Major Program of the National Natural Science Foundation of China, No.41590840, No.41590842

Author: Fang Chuanglin (1966-), PhD and Professor, specialized in urban geography, urban agglomeration and the resource and environmental effects of urbanization. E-mail: fangcl@igsnrr.ac.cn 
certain rules of regional differentiation that govern the comprehensive regionalization of Chinese human geography.

Keywords: Chinese human geography; comprehensive regionalization; spatial clustering; human geography regions; human geography sub-regions

Synthesis and regional differentiation in geography have meant that geographic zoning is a traditional task of geographical research and an important part of the discipline's development. Geographic zoning is the observation and study of a geographic entity from a regional perspective to explore the formation and development, differences and associations, divisions and amalgamations, and interrelations of spatial units. It is also a means of revealing common phenomena within regions and differences between regions, and it is the generalization and summary of processes and types of integrated research (Zheng et al., 2005). The main goal of the scientific research paradigm of geographic systems is to show the multi-factor synergistic evolution of types of geographic areas and geographic entities (Song, 2016). From ancient times, when people first attempted to create maps that separated the world, to Alexander von Humboldt, Ferdinand von Richthofen and others in modern Germany, who systematically mapped and divided Earth's surface based on their field observations (Martin, 2005), and to the flourishing of various contemporary comprehensive regionalization and thematic zoning techniques closely related to national economies and societies with the support of GIS and big data, every step of progress in geography has been closely related to the zoning of individual or integrated geographic factors, and every breakthrough in the zoning of particular geographic factors has marked the maturity of a branch of geography and the start of a new stage in the discipline's development. Comprehensive regionalization of physical geography, which concerns natural processes, has matured through the ages, while comprehensive regionalization of human geography, which concerns human processes, remains unexplored. Carrying out comprehensive regionalization of Chinese human geography will not only fill in blanks in the discipline of human geography, but, more importantly, it will help human geography better serve national and regional development strategies based on local conditions. At the international level, it will provide important theoretical support to serve the Belt and Road Strategy, strengthen exchanges and cooperation, and create a favorable geopolitical environment. At the domestic level, it will serve as an important theoretical basis for meeting national strategic needs, promoting new urbanization and environmental awareness based on local conditions, constructing rational patterns of urbanization, agricultural development and ecological security, and further optimizing the spatial pattern of land development.

\section{Relevant advances in research on comprehensive regionalization of Chinese human geography}

Although no studies have been carried out on the comprehensive regionalization of Chinese human geography to date, there have been constant developments and improvements in the zoning of individual human geographic factors in China since 1949. These zoning efforts have mainly involved the zoning of China's administration, population, economy, industry, agriculture, transport, tourism, culture, new urbanization, settlement landscape and major functions (Zheng, 2012). Of these, due to their strong association with national social and 
economic development, the most studied and discussed have been the zoning of China's economy and agriculture.

In terms of comprehensive regionalization of China's physical geography, the previous generation of geographers achieved considerable theoretical and practical results (Huang, 1959; Ren and Yang, 1961; Zhao, 1983; Yang et al., 2005). Since the 1990s, the purpose of zoning has changed to meet the needs of sustainable development, which has meant less research into human and economic zoning. As a result, in his later years, renowned Chinese geographer, Huang Bingwei, staunchly advocated studying the comprehensive regionalization of both human and physical factors (Huang, 1998). Later, Ge Quansheng, Wu Shaohong, Liu Junhui and others made initial attempts at the comprehensive regionalization of China's land surface system as well as the Qaidam Basin and the Qinghai-Tibet Plateau (Huang, 1998; Ge et al., 2003; Wu and Liu, 2005; Liu and Fu, 2005; Wu et al., 2010). A relatively influential study has been the recent one carried out on national major function-oriented zoning, which divided China's national territory into four categories, namely zones of optimal development, key development, restricted development and prohibited development. It also featured comprehensive regional divisions that integrate physical and human factors, and it has already become a basic system and national strategy for the development and protection of China's national territory (Fan, 2015). Comprehensive regionalization of human geography must take into account the effects of natural baseline factors that are inseparable from physical geography, such as the clustering of population and industry, the formation of cultural and social landscapes, and urbanization and types of agriculture. As such, to a certain extent, this research focuses more on the human and economic side of comprehensive regionalization.

To summarize, great achievements have been made in zoning in China, but there has been a complete absence of comprehensive regionalization of Chinese human geography. The current complex human and economic phenomena taking place on Earth's surface mean that zoning of individual human and economic factors is no longer capable of meeting actual needs and sustainable development objectives. Comprehensive regionalization of Chinese human geography that takes into consideration the health of the economy, social harmony, the environment and human development, and that is comprehensive, dynamic, scientific and practicable, is an area of difficult, cutting-edge work urgently in need of attention.

\section{Basis and principles of comprehensive regionalization of Chinese human geography}

\subsection{Basis of comprehensive regionalization of Chinese human geography}

The comprehensive regionalization of Chinese human geography is based on the basic division of human geography into 10 main factors, namely natural, economic, population, cultural, ethnic, agricultural, transport, urbanization, settlement landscape and administrative division factors. The division into first-level human geography regions is mainly guided by natural and economic factors, based on Zhao Songqiao's integrated physical geographic zoning, Zheng Jingyun's climate zoning scheme (Zheng et al., 2013), Fu Bojie's ecological zoning scheme (Fu et al., 2001), Ge Quansheng's land surface system zoning (Ge et al., 2002), and Yang Wuyang's economic zoning (Yang and Liang, 1992). Whereas, the division 
into second-level human geography regions is considered within a framework of the aforementioned 10 factors, this time with reference to Hu Huanyong's population zoning (Hu, 1990), Wu Bihu's culture zoning (Wu, 1996), Fang Chuanglin's new urbanization zoning (Fang et al., 2015) and Liu Peilin's settlement landscape zoning (Liu et al., 2011), as well as China's integrated agricultural zoning scheme, China's county-level administrative zoning work in 2013, and China's land transport network.

\subsection{The basic principles behind the comprehensive regionalization of Chinese human geography}

The purpose of carrying out the comprehensive regionalization of Chinese human geography is to reveal overall differences in complex human and economic systems on the land's surface, and to develop a dynamic basic platform for a Chinese human geography comprehensive regionalization proposal that provides support to multi-dimensional, multi-objective and multi-user decision-making (Liu et al., 2005). Based on this objective, comprehensive regionalization of Chinese human geography should adhere to the following five principles.

\subsubsection{Combination of the principles of synthesis and dominant factors}

The principle of synthesis refers to the inclusion, to the greatest possible extent, of the main factors influencing human geographical differences when looking at the complexity and diversity of the human geographic system, which includes nature, economy, population, culture, ethnicity, agriculture, transport, urbanization, the settlement landscape and administrative divisions. The principle of dominant factors refers to the selection of the main determining factors for different levels of zones in the course of creating each level, for example, the selection of natural ecology and economic development as the dominant factors in the division of human geography regions.

2.2.2 Combination of the principles of relative consistency of the physical environment and relative consistency of social and economic development

The layout of human economic factors is often determined, to a great extent, by underlying natural conditions. The development of Chinese human geography is based on and supported by the physical environment. In the course of zoning human geography, the first consideration was finding similarities in topographical, meteorological, climatological, hydrological and other natural conditions between human geographic units, and grouping together units with the same or similar natural conditions. Consideration was then given to finding units with similar social and economic development bases or economic structures and potential. When dividing regions, the focus was on the convergence of economic factors. Under the premise of abiding by the principle of similar natural conditions, consideration was given to areas with the same economic development bases, economic structures, types of economies, and economic potential and prospects, such as, industrial, agricultural, commercial, grassland, arable, pastoral, and forest areas, which were included in single classes, as far as possible.

2.2.3 Combination of the principles of consistency of the regional cultural landscape and consistency of ethnic and religious beliefs

Similarities and differences in regional cultures are important markers that highlight features of human geographic units. Regional culture is a precious asset inherited and passed on to 
others. It is local and rooted by nature. When carrying out the comprehensive regionalization of China's human geography, every effort was made to highlight the consistency and sense of identity of regional cultures, and to class together regional cultural areas with markedly close ties in terms of geography, kinship and culture. China is a country made up of many ethnic groups with a range of different faiths. The comprehensive regionalization of Chinese human geography needs to take into consideration the concentrations of ethnic groups as well as their religious beliefs and customs, and try as far as possible to class together regions with similar ethnic groups and religious beliefs.

\subsubsection{Combination of top-down and bottom-up principles}

Higher scale zoning is usually conducted using a top-down deductive approach; whereas, lower scale regional zoning is usually conducted using a bottom-up inductive approach (Zheng and $\mathrm{Fu}, 1999$ ). A top-down approach gives a better grasp of general trends, and a bottom-up approach is more suited to quantitative refinement analysis based on the smallest spatial unit. The zoning in this study used a combination of top-down and bottom-up approaches. A bottom-up approach was used to achieve a more accurate delineation, and a top-down approach was used to avoid excessive fragmentation and deviation from reality.

2.2.5 Combination of the principles of continuity of spatial distribution and integrity of county-level administrative divisions

Based on a consideration of the diversity and extreme complexity of the spatial differentiation of Chinese human geographic factors, while dividing human geography regions and second-level regions, the principles of continuity and choosing the large over the small in terms of spatial distribution were adhered to, and overly fragmented regions were merged appropriately to reflect the regularity and integrity of spatial differentiation in human geography. Learning from the experience of others in zoning of various Chinese physical and human geographic factors, and considering the availability of human economic data, we used county-level administrative divisions as the basic spatial unit for the comprehensive regionalization of Chinese human geography. The integrity of county boundaries was maintained and all county-level administrative units were included, but townships and towns below the level of counties were not divided further.

\section{The index system and method for comprehensive regionalization of Chinese human geography}

\subsection{Constructing the index system}

The comprehensive regionalization of Chinese human geography uses Chinese counties (including county-level cities, prefectures, banners, special districts and forest zones) and merged municipal districts officially designated in 2013 (not including Taiwan Province) as the units of research. At the end of 2013, China had 333 prefecture-level administrative districts, of which 288 were prefecture-level cities, and 2854 county-level administrative areas, of which 1425 were counties, 897 were municipal districts, 361 were county-level cities, 117 were autonomous counties, 53 were autonomous banners, and one was a forest zone. After we merged some municipal districts, there were 2285 county-level spatial units. For spatial administrative boundary vector data, 1:4,000,000 basic Chinese geographic information data 
was used.

Given the basis for the comprehensive regionalization of Chinese human geography, 12 quantifiable indicators that constitute the index system for the comprehensive regionalization of human geography were chosen (see Table 1). Data for natural ecological indicators came from the Chinese Academy of Sciences Data Centre for Resources and Environmental Sciences. County-level land areas, population, GDP, value added of primary, secondary and tertiary industries, and urban population data were taken from China County Statistical Yearbook 2014 and China Statistical Yearbook for Regional Economies 2014. Taking into account the fact that data on the average number of years in education and ethnic minority populations does not vary very much in the short-term, data on these factors was taken from China's sixth national census in 2010. The weight coefficients for each indicator were determined using an AHP (analytical hierarchy process) model supported by the entropy weight method.

Table 1 Quantitative index system and weight coefficients

\begin{tabular}{|c|c|c|c|}
\hline Factor classification & Layer indicator & $\begin{array}{c}\text { Layer weight } \\
\text { coefficient }\end{array}$ & $\begin{array}{c}\text { Factor weight } \\
\text { coefficient }\end{array}$ \\
\hline \multirow[t]{3}{*}{ Natural condition } & Altitude (m) & 0.06 & \multirow{3}{*}{0.17} \\
\hline & Aridity & 0.07 & \\
\hline & $\geqslant 10^{\circ} \mathrm{C}$ accumulated temperature & 0.04 & \\
\hline \multirow[t]{2}{*}{ Population } & Resident population $(10,000)$ & 0.08 & \multirow{2}{*}{0.18} \\
\hline & Population density (people $/ \mathrm{km}^{2}$ ) & 0.10 & \\
\hline \multirow[t]{3}{*}{ Economic indicator } & Per capita GDP (RMB) & 0.11 & \multirow{3}{*}{0.30} \\
\hline & 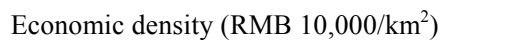 & 0.07 & \\
\hline & Industrial structure ratio (excl. agriculture) (\%) & 0.12 & \\
\hline \multirow[t]{2}{*}{ Cultural factor } & Average years of education (years) & 0.11 & \multirow{2}{*}{0.19} \\
\hline & Minority population proportion (\%) & 0.08 & \\
\hline Transport & Road network density index & 0.08 & 0.08 \\
\hline Urbanization & Level of urbanization $(\%)$ & 0.08 & 0.08 \\
\hline Total & & 1.00 & 1.00 \\
\hline
\end{tabular}

\subsection{Quantitative methods for comprehensive regionalization of Chinese human geography}

\subsubsection{Factor-weighted overlay method}

Due to differences in the basis for the division of regions, different levels of detail and differing qualities of data, as well as differences in zoning methods, the boundaries of zoned sectors are often inconsistent. The zoning in this study, however, uses the same spatial scale for each factor layer, with the division into county-level administrative spatial units achieved using ArcGIS technology (see Figure 1).

Original data was then normalized, and the entropy weight method and Delphi method were used to calculate the weight of each layer indicator. When the layers were overlaid, altitude and aridity were the first two indicators to obtain negative values. Finally, an initial human geography integrated index was calculated using the integrated index method, and an accurate level of integration of regional attributes was quantitatively assessed. The formula 


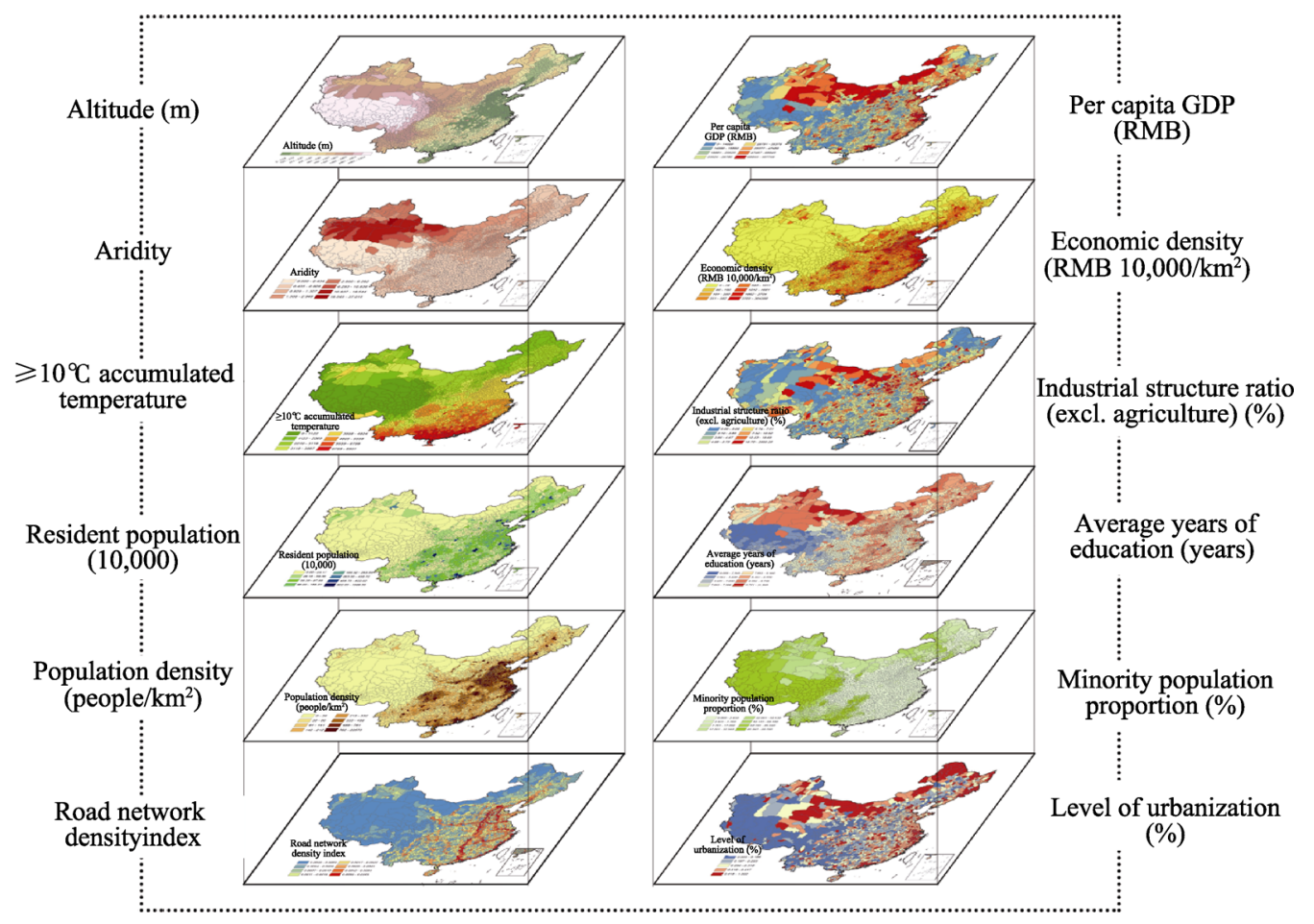

Figure 1 Visualization of factor layer overlay for comprehensive regionalization of Chinese human geography

is as follows:

$$
S=\sum_{i=1}^{n} W_{i} * S_{i}
$$

where $W_{i}$ is the weighting of the $i$ th layer, $S_{i}$ represents the attribute value of $i$ factors, and $S$ is the human geography integrated index.

\subsubsection{Spatial clustering analysis}

Spatial clustering is the clustering or classification of entities based on their characteristics and identification of clustered or densely situated areas in large multi-dimensional datasets according to a certain distance or similar measure. Data is then divided into a series of mutually differentiated groups in order to discover the overall spatial distribution laws or typical patterns of the dataset. This study used the Gomory-Hu tree algorithm and Euclidean-based k-means clustering algorithm to carry out spatial clustering of the human geography integrated index.

\subsubsection{Experts' experience and comparative analysis of zoning}

In the course of quantitative research, differences in the selection of indicators, the assignment of weightings and clustering algorithms, mean that zoning results differ. As a result, during research on the human geography comprehensive regionalization proposal, having acquired quantitative zoning results, it was necessary to make full use of the experience of experts to make small corrections to computer results to avoid excessive fragmentation and obvious errors. For traditional cultural areas, settlement landscape areas and agricultural 
areas that have not been quantified, it was also necessary to carry out a comparative analysis with the clustering results in order to optimize the proposal as much as possible.

\section{Comprehensive regionalization of Chinese human geography proposal}

In accordance with the Chinese human geographic zoning basis, zoning principles and zoning index system, and using the factor-weighted overlay method, spatial clustering algorithm and expert experience, this paper divided China into eight major human geography regions and 66 human geography sub-regions. Here, the naming of the human geographic units is an important link in the comprehensive regionalization of Chinese human geography, as it indicates the hierarchy and characteristics of different integrated zones of human geography. In this study, the comprehensive regionalization of Chinese human geography is divided into two levels: human geography regions (first-level) and human geography sub-regions (second-level). The main factors of first-level regions are economic and natural ecological factors; therefore, they are named according to the type of large economic zones, for example, the Northeast, North, Northwest and South regions. Second-level regions are named after a combination of physical geographic or administrative unit names, such as the BeijingTianjin Urban Human Geography Sub-region, Southern Zhejiang Human Geography Subregion, Hexi Corridor Human Geography Sub-region, and Qinba Mountains Human Geography Sub-region.

\subsection{Generating and delineating Chinese human geography regions}

In the course of dividing Chinese human geography into regions, the dominant integrated factors considered were natural and economic conditions. After calculating the natural ecological index and integrated economic index at the county level for the whole of China according to the layer weights in Table 1, and using existing physical geographic zoning regions and economic zoning regions as an extra reference, we divided the country into the following eight human geography regions: (I) Northeast China Human Geography Region, (II) North China Human Geography Region, (III) East China Human Geography Region, (IV) Central China Human Geography Region, (V) South China Human Geography Region, (VI) Northwest China Human Geography Region, (VII) Southwest China Human Geography Region, and (VIII) Qinghai and Tibet Human Geography Region. The scopes and basic profiles of the administrative divisions for each human geography region are given in Table 2. The table also contains social and economic development data for each region. The South China Human Geography Region has the highest per capita GDP, industrial structure ratio (excluding agriculture) and level of urbanization. The Central China Human Geography Region has the largest population, but it lags behind in terms of economic and urbanization indicators.

\subsection{Generating and delineating Chinese human geography sub-regions (second-level)}

Having divided Chinese human geography into zones, and with overall consideration given to the 10 major elements (nature, economy, population, culture, ethnicity, agriculture, transportation, urbanization, the settlement landscape and administrative divisions), we used weighted overlay analysis to calculate the Chinese human geography comprehensive regionalization index (see Figure 2). It can be seen from the figure that several areas with 
Table 2 Administrative scopes and basic profiles of Chinese human geography regions

\begin{tabular}{|c|c|c|c|c|c|c|c|}
\hline $\begin{array}{l}\text { Region } \\
\text { No. }\end{array}$ & $\begin{array}{l}\text { Name of } \\
\text { Human } \\
\text { Geography } \\
\text { Region }\end{array}$ & $\begin{array}{l}\text { Administrative divisions } \\
\text { included in scope }\end{array}$ & $\begin{array}{c}\text { Area } \\
(10,000 \mathrm{~s} \\
\left.\mathrm{km}^{2}\right)\end{array}$ & $\begin{array}{l}\text { Resident } \\
\text { population } \\
(10,000 \mathrm{~s})\end{array}$ & $\begin{array}{c}\text { Per capita } \\
\text { GDP (RMB } \\
10,000 / \\
\text { person) }\end{array}$ & $\begin{array}{l}\text { Industrial } \\
\text { structure } \\
\text { ratio (excl. } \\
\text { agriculture) } \\
\quad(\%)\end{array}$ & $\begin{array}{l}\text { Level of } \\
\text { urbaniza- } \\
\text { tion }(\%)\end{array}$ \\
\hline I & $\begin{array}{l}\text { Northeast } \\
\text { China }\end{array}$ & $\begin{array}{l}\text { Heilongjiang, Liaoning, Jilin, } \\
\text { eastern Inner Mongolia }\end{array}$ & 142.77 & 11873.59 & 6.15 & 90.23 & 57.33 \\
\hline II & North China & $\begin{array}{l}\text { Beijing, Tianjin, Hebei, Shanxi, } \\
\text { northern and central Shandong, } \\
\text { central Inner Mongolia }\end{array}$ & 69.75 & 23476.27 & 6.48 & 93.91 & 52.52 \\
\hline III & East China & $\begin{array}{l}\text { Zhejiang, Jiangsu, Anhui, } \\
\text { southern Shandong }\end{array}$ & 37.38 & 23803.07 & 7.46 & 95.16 & 57.00 \\
\hline IV & $\begin{array}{l}\text { Central } \\
\text { China }\end{array}$ & $\begin{array}{l}\text { Hubei, Jiangxi, Hunan, central } \\
\text { and eastern Henan, southern } \\
\text { Guizhou, southeast Chongqing }\end{array}$ & 74.98 & 25757.72 & 4.08 & 89.49 & 42.56 \\
\hline V & South China & $\begin{array}{l}\text { Fujian, Guangzhou, Taiwan, } \\
\text { Hainan, eastern and western } \\
\text { Guangxi, Hong Kong and Macau } \\
\text { SARs }\end{array}$ & 71.14 & 22431.98 & 9.71 & 95.76 & 60.34 \\
\hline VI & $\begin{array}{l}\text { Northwest } \\
\text { China }\end{array}$ & $\begin{array}{l}\text { Shaanxi, Ningxia, Xinjiang, cen- } \\
\text { tral and northern Gansu, western } \\
\text { Inner Mongolia, northeast } \\
\text { Qinghai, western Henan }\end{array}$ & 288.25 & 10120.29 & 4.30 & 90.53 & 44.18 \\
\hline VII & $\begin{array}{l}\text { Southwest } \\
\text { China }\end{array}$ & $\begin{array}{l}\text { Yunnan, eastern Sichuan, south- } \\
\text { west and northern Chongqing, } \\
\text { western Guizhou }\end{array}$ & 91.39 & 19762.58 & 3.40 & 88.61 & 40.24 \\
\hline VIII & $\begin{array}{l}\text { Qinghai and } \\
\text { Tibet }\end{array}$ & $\begin{array}{l}\text { Tibet, central and western Qing- } \\
\text { hai, western Sichuan, southern } \\
\text { Gansu }\end{array}$ & 256.99 & 964.19 & 2.33 & 84.40 & 24.65 \\
\hline
\end{tabular}

similar integrated human geography attributes are clustered together and coincide with the divisions into human geography regions. The result of the Moran's I index was 0.17 , below the $1 \%$ significance level, with a $\mathrm{Z}$ value of 33.59 , which indicates significant spatial auto correlation. Given the significant spatial dependence, further spatial clustering analysis was carried out, in which spatial units that are close and have converging attributes were clustered together. Quantitative clustering analysis provided the basis for further dividing second-level Chinese human geography regions. This was combined with top-down qualitative analysis, which took into consideration the fact that second-level human geography regions are subdivisions of human geography regions, on the one hand, while on the other, the need to repeatedly compare the zoning of cultural, agricultural and settlement landscape areas with the boundaries of human geography integrated index clusters. Ultimately, 66 human geography sub-regions were delineated (see Figure 3 and Table 3).

\subsection{Process and proposal for comprehensive regionalization of Chinese human geography}

The process of generating and planning the division of Chinese human geography regions (firstlevel) and Chinese human geography sub-regions (second-level) was guided by the Chinese human geography comprehensive regionalization proposal made up of eight major human geography regions and 66 human geography sub-regions (see Figure 3). The human 


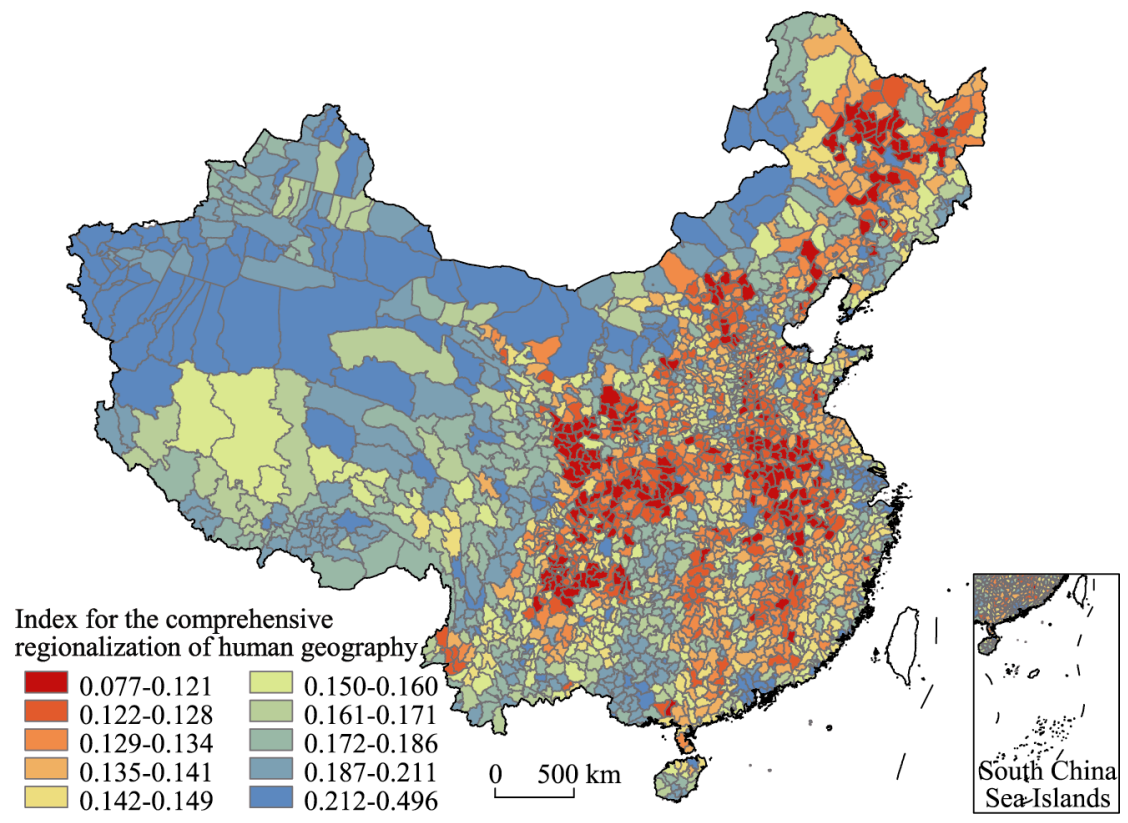

Figure 2 Comprehensive regionalization index results from the weighted overlay of Chinese human geographic factors

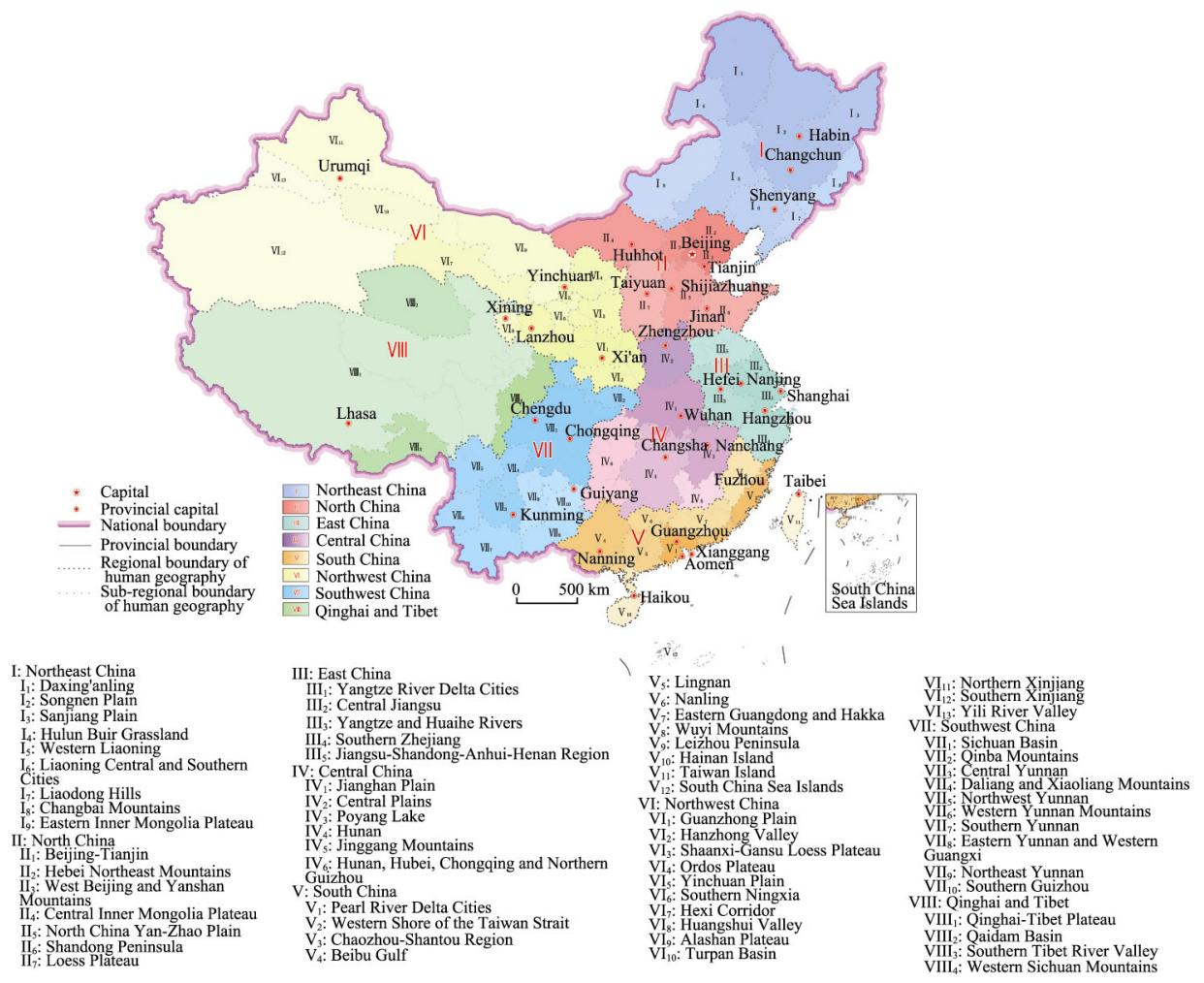

Figure 3 Comprehensive regionalization of Chinese human geography 
Table 3 Chinese human geography regions and sub-regions

\begin{tabular}{|c|c|c|}
\hline $\begin{array}{l}\text { Name of human } \\
\text { geography region } \\
\quad \text { (first-level) }\end{array}$ & Name of human geography sub-regions (second-level) & $\begin{array}{l}\text { Number of } \\
\text { sub-regions }\end{array}$ \\
\hline Northeast China (I) & $\begin{array}{l}\text { Daxing'anling }\left(\mathrm{I}_{1}\right) \text {, Songnen Plain }\left(\mathrm{I}_{2}\right) \text {, Sanjiang Plain }\left(\mathrm{I}_{3}\right) \text {, Hulun Buir Grass- } \\
\text { land }\left(\mathrm{I}_{4}\right) \text {, Western Liaoning }\left(\mathrm{I}_{5}\right) \text {, Liaoning Central and Southern Cities }\left(\mathrm{I}_{6}\right) \text {, } \\
\text { Liaodong Hills }\left(\mathrm{I}_{7}\right) \text {, Changbai Mountains }\left(\mathrm{I}_{8}\right) \text {, Eastern Inner Mongolia Plateau }\left(\mathrm{I}_{9}\right)\end{array}$ & 9 \\
\hline North China (II) & $\begin{array}{l}\text { Beijing-Tianjin }\left(\mathrm{II}_{1}\right) \text {, Hebei Northeast Mountains }\left(\mathrm{II}_{2}\right) \text {, West Beijing and Yan- } \\
\text { shan Mountains }\left(\mathrm{II}_{3}\right) \text {, Central Inner Mongolia Plateau }\left(\mathrm{II}_{4}\right) \text {, North China } \\
\text { Yan-Zhao Plain }\left(\mathrm{II}_{5}\right) \text {, Shandong Peninsula }\left(\mathrm{II}_{6}\right) \text {, Loess Plateau }\left(\mathrm{II}_{7}\right)\end{array}$ & 7 \\
\hline East China (III) & $\begin{array}{l}\text { Yangtze River Delta Cities }\left(\mathrm{III}_{1}\right) \text {, Central Jiangsu }\left(\mathrm{III}_{2}\right) \text {, Yangtze and Huaihe } \\
\text { Rivers }\left(\mathrm{III}_{3}\right) \text {, Southern Zhejiang }\left(\mathrm{III}_{4}\right) \text {, Jiangsu-Shandong-Anhui-Henan Region }\left(\mathrm{III}_{5}\right)\end{array}$ & 5 \\
\hline Central China (IV) & $\begin{array}{l}\text { Jianghan Plain }\left(\mathrm{IV}_{1}\right) \text {, Central Plains }\left(\mathrm{IV}_{2}\right) \text {, Poyang Lake }\left(\mathrm{IV}_{3}\right) \text {, Hunan }\left(\mathrm{IV}_{4}\right) \text {, } \\
\text { Jinggang Mountains }\left(\mathrm{IV}_{5}\right) \text {, Hunan, Hubei, Chongqing and Northern Guizhou }\left(\mathrm{IV}_{6}\right)\end{array}$ & 6 \\
\hline South China (V) & $\begin{array}{l}\text { Pearl River Delta Cities }\left(\mathrm{V}_{1}\right) \text {, Western Shore of the Taiwan Strait }\left(\mathrm{V}_{2}\right) \text {, } \\
\text { Chaozhou-Shantou Region }\left(\mathrm{V}_{3}\right) \text {, Beibu Gulf }\left(\mathrm{V}_{4}\right) \text {, Lingnan }\left(\mathrm{V}_{5}\right) \text {, Nanling }\left(\mathrm{V}_{6}\right) \text {, } \\
\text { Eastern Guangdong and Hakka }\left(\mathrm{V}_{7}\right) \text {, Wuyi Mounatins }\left(\mathrm{V}_{8}\right) \text {, Leizhou Peninsula } \\
\left(\mathrm{V}_{9}\right) \text {, Hainan Island }\left(\mathrm{V}_{10}\right) \text {, Taiwan Island }\left(\mathrm{V}_{11}\right) \text {, South China Sea Islands }\left(\mathrm{V}_{12}\right)\end{array}$ & 12 \\
\hline Northwest China (VI) & $\begin{array}{l}\text { Guanzhong Plain }\left(\mathrm{VI}_{1}\right) \text {, Hanzhong Valley }\left(\mathrm{VI}_{2}\right) \text {, Shaanxi-Gansu Loess Plateau } \\
\left(\mathrm{VI}_{3}\right) \text {, Ordos Plateau }\left(\mathrm{VI}_{4}\right) \text {, Yinchuan Plain }\left(\mathrm{VI}_{5}\right) \text {, Southern Ningxia }\left(\mathrm{VI}_{6}\right) \text {, Hexi } \\
\text { Corridor }\left(\mathrm{VI}_{7}\right) \text {, Huangshui Valley }\left(\mathrm{VI}_{8}\right) \text {, Alashan Plateau }\left(\mathrm{VI}_{9}\right) \text {, Turpan Basin } \\
\left(\mathrm{VI}_{10}\right) \text {, Northern Xinjiang }\left(\mathrm{VI}_{11}\right) \text {, Southern Xinjiang }\left(\mathrm{VI}_{12}\right) \text {, Yili River Valley }\left(\mathrm{VI}_{13}\right)\end{array}$ & 13 \\
\hline $\begin{array}{l}\text { Southwest China } \\
\text { (VII) }\end{array}$ & $\begin{array}{l}\text { Sichuan Basin }\left(\mathrm{VII}_{1}\right) \text {, Qinba Mountains }\left(\mathrm{VII}_{2}\right) \text {, Central Yunnan }\left(\mathrm{VII}_{3}\right) \text {, Daliang } \\
\text { and Xiaoliang Mountains }\left(\mathrm{VII}_{4}\right) \text {, Northwest Yunnan }\left(\mathrm{VII}_{5}\right) \text {, Western Yunnan } \\
\text { Mountains }\left(\mathrm{VII}_{6}\right) \text {, Southern Yunnan }\left(\mathrm{VII}_{7}\right) \text {, Eastern Yunnan and Western } \\
\text { Guangxi }\left(\mathrm{VII}_{8}\right) \text {, Northeast Yunnan }\left(\mathrm{VII}_{9}\right) \text {, Southern Guizhou }\left(\mathrm{VII}_{10}\right)\end{array}$ & 10 \\
\hline $\begin{array}{l}\text { Qinghai and Tibet } \\
\text { (VIII) }\end{array}$ & $\begin{array}{l}\text { Qinghai-Tibet Plateau }\left(\mathrm{VIII}_{1}\right) \text {, Qaidam Basin }\left(\mathrm{VIII}_{2}\right) \text {, Southern Tibet River } \\
\text { Valley }\left(\mathrm{VIII}_{3}\right) \text {, Western Sichuan Mountains }\left(\mathrm{VIII}_{4}\right)\end{array}$ & 4 \\
\hline Totals & 66 & 66 \\
\hline
\end{tabular}

geography sub-regions have different topographical, climatic, ecological, population, urbanization, economic development, settlement landscape, regional cultural and ethno-religious attributes. A comparative analysis of human geography regions and sub-regions was omitted due to space limitations. Overall, the comprehensive regionalization of Chinese human geography into regions dovetails closely with Yang Wuyang's eight economic zones (Yang and Liang, 1992), Ge Quansheng et al.'s nine land surface system zones (Ge et al., 2002), and the 10 first-level Chinese integrated agricultural zones, and it shows that, under the dual roles of nature and humans, there are certain rules of regional differentiation that govern comprehensive regionalization. At the same time, there are many differences. For example, eastern Xilin Gol, Tongliao and the Chifeng region in Inner Mongolia are included in the Northeast China Human Geography Region, due to their economic ties, language and cultural identity being closer to those of northeast China; Xining is included in the Northwest China Human Geography Region, and not in the Qinghai-Tibet Human Geography Region as one might expect based on its physical geographic boundary, primarily due to its close ties with the Lanzhou-Xining urban agglomeration and its development trajectory; and due to the complexity of its terrain, ethnic diversity and varied cultural landscape, the Southwest China Human Geography Region is divided into many relatively small second-level regions. 


\section{Conclusion and discussion}

\subsection{Conclusion}

The comprehensive regionalization of Chinese human geography is based on the rules of geographical differentiation of Chinese physical geographic factors and takes as its basis 10 human geographic factors (nature, economy, population, culture, ethnicity, agriculture, transportation, urbanization, the settlement landscape and administrative divisions). With full consideration given to the geographical differences and similarities in human factors across China, the country was divided into different spatial levels and relatively independent, complete and organically linked special human geographic units. There are regional differences in human factors between human geographic units, but regional similarities in human factors within units. Compared to previous zoning studies, the comprehensive regionalization of Chinese human geography is more integrated and dynamic. The comprehensive regionalization of human geography highlights the characteristics, regional and sub-regional features, complexity and variety of spatial differences between factors of Chinese human geography. It can promote the development of human geography based on local conditions, and provide basic scientific support to national and local development strategies, such as the Belt and Road, new urbanization and raising environmental awareness, as well as creating a sound geopolitical environment in key areas.

In accordance with the principles of synthesis, dominant factors, the relative consistency of the natural environment, the relative consistency of social and economic development, the consistency of the regional cultural landscape, the continuity of spatial distribution and the integrity of county-level administrative divisions, an index system for the comprehensive regionalization of Chinese human geography was constructed and a combination of top-down and bottom-up zoning and spatial clustering analysis methods was used to divide Chinese human geography into eight regions and 66 sub-regions. The eight regions are (I) Northeast China, (II) North China, (III) East China, (IV) Central China, (V) South China, (VI) Northwest China, (VII) Southwest China, and (VIII) Qinghai and Tibet. Each human geography region and sub-region has different topographical, climatic, ecological, population, urbanization, economic development, settlement landscape, regional cultural and ethno-religious attributes.

This proposal for the comprehensive regionalization of Chinese human geography dovetails closely with previous studies on comprehensive regionalization in Chinese physical geography, Chinese economic zoning, and Chinese agricultural zoning, and it shows that, under the dual roles of nature and humans, there are certain rules of regional differentiation that govern the comprehensive regionalization of Chinese human geography.

\subsection{Discussion}

5.2.1 The dynamic nature and elasticity of zoning in the comprehensive regionalization of Chinese human geography

Due to the increasing fluidity of population, resources, capital, and information across space and time, unlike physical geographic factors, the geographical distribution of human geographic factors is unstable and changing relatively quickly. The fluidity of such factors and 
the rootedness of regional cultures are facts that have been known and components that have interacted for a long time, which means the comprehensive regionalization of Chinese human geography must be flexible enough to adapt to change. On the one hand, increasing dynamic adjustments to the temporal dimension improves the quantitative index system and method of zoning, and on the other hand, dynamically adjusting the leading factors or factor weightings of zoning based on practical application requirements, and under an integrated framework with different objectives, expands the applications of this type of zoning. As such, construction of a dynamic monitoring system for Chinese human geographic zoning with space-time bidirectional dimensions and goal-oriented functions, as well as development of dynamic identification and simulation software for comprehensive regionalization of Chinese human geography, are urgent tasks.

5.2.2 Refining the comprehensive regionalization of Chinese human geography and the issue of third-level regions

Having divided Chinese human geography into regions and sub-regions, a question worth looking at is how to divide it into districts (third-level). Difficulties include how to choose the main factors for the division of third-level regions (districts) and which zoning method should be used at the smaller scale. The division of human geography into districts could play an important role in supporting the development of regional urban and rural integration and coordinating with major function-oriented zones at the county level.

5.2.3 The forecasting and guiding functions of comprehensive regionalization of Chinese human geography in regional development and the issue of transcending zoning

In the past, the zoning of single human geographic factors was mostly static and served individual purposes. Comprehensive regionalization of Chinese human geography, on the other hand, focuses on being comprehensive and dynamic. It adopts a systems holism approach in order to provide basic theoretical guidance for the benign evolution of complex socio-economic and ecological systems. As the theory and practice of zoning matures, it will spawn more derivative applications and play more of a guiding role in predicting regional development potential, adjusting the layout of industries, selecting public services and allocating regional materials and resources. Zoning will transcend mere lines on a map to become closely integrated with China's regional strategy and a way of predicting and guiding the future.

\section{Acknowledgements}

The authors thank the following people for their valuable suggestions and guidance in the course of writing this paper: Professor Zheng Du, Academician of the Chinese Academy of Sciences; Professor Li Wenhua, Academician of the Chinese Academy of Engineering; Professor Song Changqing from Beijing Normal University; Professor Kong Deyong from the Chinese Academy of Science and Technology for Development; Professor Mao Hanying from the International Eurasian Academy of Sciences; Professor Cai Yunlong from Peking University; Professor Zhou Shangyi from Beijing Normal University; Professor Wu Shaohong from the Institute of Geographic Sciences and Natural Resources Research at the Chinese Academy of Sciences; Professor Zhang Guoyou from the Geographical Society of 
China; Professor He Shujin, Managing Director of the Editorial Office of Acta Geographica Sinica; and Professor Shen Yuming from Capital Normal University.

\section{References}

Fan Jie, 2015. Draft of major function oriented zoning of China. Acta Geographica Sinica, 70(2): 186-201. (in Chinese)

Fang Chuanglin, Ma Haitao, Wang Jing, 2015. A regional categorization for "New-Type Urbanization" in China. PloS One, 10(8): 1-20.

Fu Bojie, Liu Guohua, Chen Liding et al., 2001. Scheme of ecological regionalization in China. Acta Ecologica Sinica, 21(1): 1-6. (in Chinese)

Ge Quansheng, Zhao Mingcha, Zheng Jingyun et al., 2002. Study on division of the terrestrial system in China. Acta Geographica Sinica, 57(5): 515-522. (in Chinese)

Ge Quansheng, Zhao Mingcha, Zheng Jingyun et al., 2003. Division of the terrestrial system in China: A case study from Huang's theory on terrestrial system science. Scientia Geographica Sinica, 23(1): 1-6. (in Chinese)

$\mathrm{Hu}$ Huanyong, 1990. The distribution, regionalization and prospect of China's population. Acta Geographica Sinica, 45(2): 139-145. (in Chinese)

Huang Bingwei, 1959. A preliminary draft of comprehensive physical regionalization in China. Chinese Science Bulletin, 4(18): 594-602. (in Chinese)

Huang Bingwei, 1998. Comprehensive study of geography and interdisciplinary. Science Monthly, 50(5): 3-5. (in Chinese)

Liu Junhui, Fu Xiaofeng, 2005. Discussion on method of China's sustainable development integrated regional planning. China Population Resources and Environment, 15(4): 11-16. (in Chinese)

Liu Peilin, Liu Chunla, Deng Yunyuan et al., 2011. Landscape division of traditional settlement and effect elements of landscape gene in China. Acta Geographica Sinica, 65(12): 1496-1506. (in Chinese)

Liu Yanhua, Zheng Du, Ge Quansheng et al., 2005. Problems on the research of comprehensive regionalization in China. Geographical Research, 24(3): 321-329. (in Chinese)

Martin G J, 2005. All Possible Worlds: A History of Geographical Ideas. London: OUP Catalogue.

Ren Mei'e, Yang Renzhang, 1961. Physical regionalization in China. Acta Geographica Sinica, 27(12): 66-74. (in Chinese)

Song Changqing, 2016. On paradigms of geographical research. Progress in Geography, 35(1): 1-3. (in Chinese)

Wu Bihu, 1996. Partition and the formation of the Chinese culture areas. Academic Monthly, (3): 10-15. (in Chinese)

Wu Shaohong, Liu Weidong, 2005. An integrated approach to classification of territorial systems: A case study of the Tibetan Plateau. Geographical Research, 24(2): 169-177, 321. (in Chinese)

Wu Shaohong, Yin Yunhe, Fan jie et al., 2010. Retrospect and prospect of regionalization system of China. Geographical Research, 29(9): 1538-1545. (in Chinese)

Yang Qinye, Zheng Du, Wu Shaohong et al., 2005. Review and prospects: Integrated physical geography in China since the 1950s. Geographical Research, 24(6): 899-910. (in Chinese)

Yang Wuyang, Liang Jinshe, 1992. China's ten economic zones. Economic Geography, 12(3): 14-20. (in Chinese)

Zhao Songqiao, 1983. A new scheme of comprehensive physical regionalization in China. Acta Geographica Sinica, 38(1): 1-10. (in Chinese)

Zheng Du, 2012. Dictionary of Geographical Regionalization and Planning. Beijing: China Waterpower Press. (in Chinese)

Zheng Du, Fu Xiaofeng, 1999. A preliminary study on issues of integrated geographical regionalization. Scientia Geographica Sinica, 19(3): 193-197. (in Chinese)

Zheng Du, Ge Quansheng, Zhang Xueqin et al., 2005. Regionalization in China: Retrospect and prospect. Geographical Research, 24(3): 330-344. (in Chinese)

Zheng Jingyun, Bian Juanjuan, Ge Quansheng et al., 2013. The climate regionalization in China for 1981-2010. Chinese Science Bulletin, 58(30): 3088-3099. (in Chinese) 